\title{
Improvement of multiple intraperitoneal nodules resembling peritoneal cancer that developed after peritoneal dialysis-related peritonitis caused by Mycobacterium abscessus with literature review: granuloma or carcinoma
}

Kohsuke Terada, Tomohiro Yan, Koji Mugishima, Sayuri Kawasaki, Fumiaki Itagaki, Takehisa Yamada and Yukinao Sakai

\begin{abstract}
Introduction: Peritonitis is a crucial complication that leads to hospitalization or even death in patients who are undergoing peritoneal dialysis (PD). The incidence of PD-related peritonitis associated with nontuberculous mycobacteria has increased in recent years. However, a well-established treatment for peritonitis is lacking, particularly in peritonitis caused by Mycobacterium abscessus which is a difficult to treat disease due to its inherent resistance to majority of available antibiotics. To the best of our knowledge, this case is the first to report on intraperitoneal multiple nodules that developed due to PD-related peritonitis caused by M. abscessus.

Case presentation: This case reported a case of a 40-year-old female patient who was undergoing PD and who showed multiple intraperitoneal nodules that resembled peritoneal cancer on computed tomography (CT) and that developed after PD-related peritonitis and catheter removal. After multiantibiotic therapy, multiple nodules were found to have disappeared on CT. The nodules continued to disappear and the patient did not show signs of recurrent peritonitis, although there was a possibility of recurrence.
\end{abstract}

Conclusion: To the best of our knowledge, this case is the first to report on nodules that resembled peritoneal cancer and that developed in the abdominal cavity due to PD-related peritonitis caused by M. abscessus. Positron emission tomography-CT was not useful in distinguishing peritoneal cancer from nodules caused by M. abscessus.

Keywords: Peritoneal dialysis, Mycobacterium abscessus, Intraperitoneal, Nodule, Granuloma

* Correspondence: y-sakai@nms.ac.jp

Department of Nephrology, Graduate School of Medicine, Nippon Medical

School, 1-1-5 Sendagi, Bunkyo-ku, Tokyo 113-8603, Japan

C C The Author(s). 2020 Open Access This article is licensed under a Creative Commons Attribution 4.0 International License, which permits use, sharing, adaptation, distribution and reproduction in any medium or format, as long as you give appropriate credit to the original author(s) and the source, provide a link to the Creative Commons licence, and indicate if changes were made. The images or other third party material in this article are included in the article's Creative Commons licence, unless indicated otherwise in a credit line to the material. If material is not included in the article's Creative Commons licence and your intended use is not permitted by statutory regulation or exceeds the permitted use, you will need to obtain permission directly from the copyright holder. To view a copy of this licence, visit http://creativecommons.org/licenses/by/4.0/ The Creative Commons Public Domain Dedication waiver (http://creativecommons.org/publicdomain/zero/1.0/) applies to the data made available in this article, unless otherwise stated in a credit line to the data. 


\section{Introduction}

Peritonitis is a crucial complication that leads to hospitalization or even death in patients who are undergoing peritoneal dialysis (PD). It is one of the primary reasons for the shift from PD to hemodialysis in patients. PD-related peritonitis associated with nontuberculous mycobacteria is uncommon, but its incidence has increased in recent years [1]. Moreover, a well-established treatment for peritonitis caused by nontuberculous mycobacteria is lacking, and affected patients generally require catheter removal [1]. Hence, peritonitis associated with nontuberculous mycobacterial infection is considered as a complication of PD that is difficult to treat, particularly peritonitis which is caused by Mycobacterium abscessus, a rapidly growing mycobacteria, and which is a difficult to treat disease due to its inherent resistance to majority of available antibiotics [2, 3]. Moreover, only a few reports have described that $M$. abscessus can cause nodules in the lungs [2]. However, there are no reports describing about intraperitoneal multiple nodules caused by PD-related peritonitis associated with M. abscessus infection. This case reported a case of a patient who exhibited multiple intraperitoneal nodules resembling peritoneal cancer on computed tomography (CT) that developed after PD-related peritonitis. It was further found that after catheter removal and multiantibiotic therapy, the nodules disappeared.

\section{Case presentation}

A 40-year-old woman with diabetic nephropathy underwent PD for 5 months. She had history of the use of topical gentamicin cream to prevent exit-site infection. She presented to the hospital with a fever $\left(38.3^{\circ} \mathrm{C}\right)$ and a cloudy peritoneal effluent without abdominal pain. The patient's dialysis effluent and the pus leaking from the exit site were examined. No redness was observed but swelling and pain around the exit site was noted. The patient did not manifest abdominal tenderness and diarrhea. The patient has edema of both legs due to hypoalbuminemia. The white blood cell (WBC) count in the effluent was $200 / \mu \mathrm{L}$ with $75 \%$ polymorphonuclear leukocytes. Based on this finding, the patient was diagnosed with PD-related peritonitis. Table 1 presents the laboratory findings at the time of admission. A complete blood count of the patient showed an elevated WBC count with a predominance of neutrophils. Furthermore, she had high serum $\mathrm{C}$-reactive protein (CRP) and procalcitonin levels. CT showed an increase in the patient's attenuation of fatty tissues around the PD catheter and the external cuff, but there were no nodules in peritoneal cavity. The patient was initially treated as a case of PDrelated peritonitis due to the infection at the exit site. At the first day of hospitalization, treatment with cefazolin (CEZ) through intravenous (IV) administration and
Table 1 Laboratory findings recorded on the first day of admission

\begin{tabular}{|c|c|c|c|c|c|}
\hline \multicolumn{6}{|c|}{ Laboratory findings at the 1st admission } \\
\hline \multicolumn{2}{|c|}{ Urinalysis } & \multirow{2}{*}{$\begin{array}{l}\text { T-Bil } \\
\text { LDH }\end{array}$} & \multirow{2}{*}{$\begin{array}{l}0.2 \mathrm{mg} / \\
\mathrm{dL} \\
295 \mathrm{IU} / \mathrm{L}\end{array}$} & \multicolumn{2}{|l|}{ Serology } \\
\hline Protein & $(3+)$ & & & CRP & $\begin{array}{l}25.30 \mathrm{mg} / \\
\mathrm{dL}\end{array}$ \\
\hline $\begin{array}{l}\text { Occult } \\
\text { blood }\end{array}$ & $(1+)$ & CK & $252 \mathrm{IU} / \mathrm{L}$ & $\lg G$ & $\begin{array}{l}735 \mathrm{mg} / \\
\mathrm{dL}\end{array}$ \\
\hline WBC & $(-)$ & TP & $4.9 \mathrm{~g} / \mathrm{dL}$ & $\lg A$ & $\begin{array}{l}256 \mathrm{mg} / \\
\mathrm{dL}\end{array}$ \\
\hline bacteria & $(-)$ & Alb & $1.9 \mathrm{~g} / \mathrm{dL}$ & $\lg M$ & $\begin{array}{l}108 \mathrm{mg} / \\
\mathrm{dL}\end{array}$ \\
\hline $\mathrm{CBC}$ & & BUN & $\begin{array}{l}50.7 \mathrm{mg} / \\
\mathrm{dL}\end{array}$ & Procalcitonin & $\begin{array}{l}1.66 \mathrm{ng} / \\
\mathrm{mL}\end{array}$ \\
\hline WBC & $13,900 / \mu \mathrm{L}$ & Cre & $\begin{array}{l}7.72 \mathrm{mg} / \\
\mathrm{dL}\end{array}$ & Coagulation & \\
\hline RBC & $\begin{array}{l}375 \times 10 \wedge 4 / \\
\mu \mathrm{L}\end{array}$ & T-Cho & $\begin{array}{l}220 \mathrm{mg} / \\
\mathrm{dL}\end{array}$ & APTT & $34.6 \mathrm{~s}$ \\
\hline $\mathrm{Hb}$ & $11.2 \mathrm{~g} / \mathrm{dL}$ & $\begin{array}{l}\text { LDL- } \\
\text { Cho }\end{array}$ & $\begin{array}{l}141 \mathrm{mg} / \\
\mathrm{dL}\end{array}$ & PT & $89.70 \%$ \\
\hline $\mathrm{Hct}$ & $33.80 \%$ & TG & $\begin{array}{l}63 \mathrm{mg} / \\
\mathrm{dL}\end{array}$ & D-dimer & $3.8 \mu \mathrm{g} / \mathrm{mL}$ \\
\hline Plt & $\begin{array}{l}37.1 \times \\
10^{\wedge} 4 / \mu \mathrm{L}\end{array}$ & $\mathrm{Na}$ & $\begin{array}{l}133 \\
\mathrm{mEq} / \mathrm{L}\end{array}$ & Effluent & \\
\hline \multicolumn{2}{|c|}{ Biochemical } & K & $\begin{array}{l}4.8 \mathrm{mEq} / \\
\mathrm{L}\end{array}$ & WBC & $200 / \mu \mathrm{L}$ \\
\hline AST & $14 \mathrm{IU} / \mathrm{L}$ & $\mathrm{Cl}$ & $\begin{array}{l}96 \mathrm{mEq} / \\
\mathrm{L}\end{array}$ & Neutrophil & $75 \%$ \\
\hline ALT & $9 \mathrm{IU} / \mathrm{L}$ & Glucose & $\begin{array}{l}118 \mathrm{mg} / \\
\mathrm{dL}\end{array}$ & & \\
\hline
\end{tabular}

ceftazidime (CAZ) through intraperitoneal (IP) administration (Fig. 1) was started. The medicines were not found to be effective as the patient's clinical symptoms such as high fever and diarrhea starting after the admission showed no improvement, and the effluent continued to be cloudy. Hence, the treatment was replaced with meropenem (MEPM) through IV administration and cefozopran (CZOP) through IP. Culture of the PD effluent and pus revealed the presence of Gram-positive rod-shaped bacteria such as Corynebacterium; hence, $1.6 \mathrm{~g} /$ day of sulfamethoxazole and $320 \mathrm{mg} /$ day of trimethoprim (ST) through peroral (PO) administration were added. After the change in treatment, a gradual improvement on the patient's peritonitis was observed. Thus, CZOP and MEPM were discontinued. However, de-escalation of antibiotics was not attempted as the antibiotic sensitivity of the bacteria found in the PD effluent and pus was not determined and the blood culture was also negative. Improvement in the clinical status and pus at the exit site was observed; hence, the patient was discharged from the hospital. However, 3 days after the discharge, she was hospitalized again due to recurring exacerbations of high fever and pus leaking 


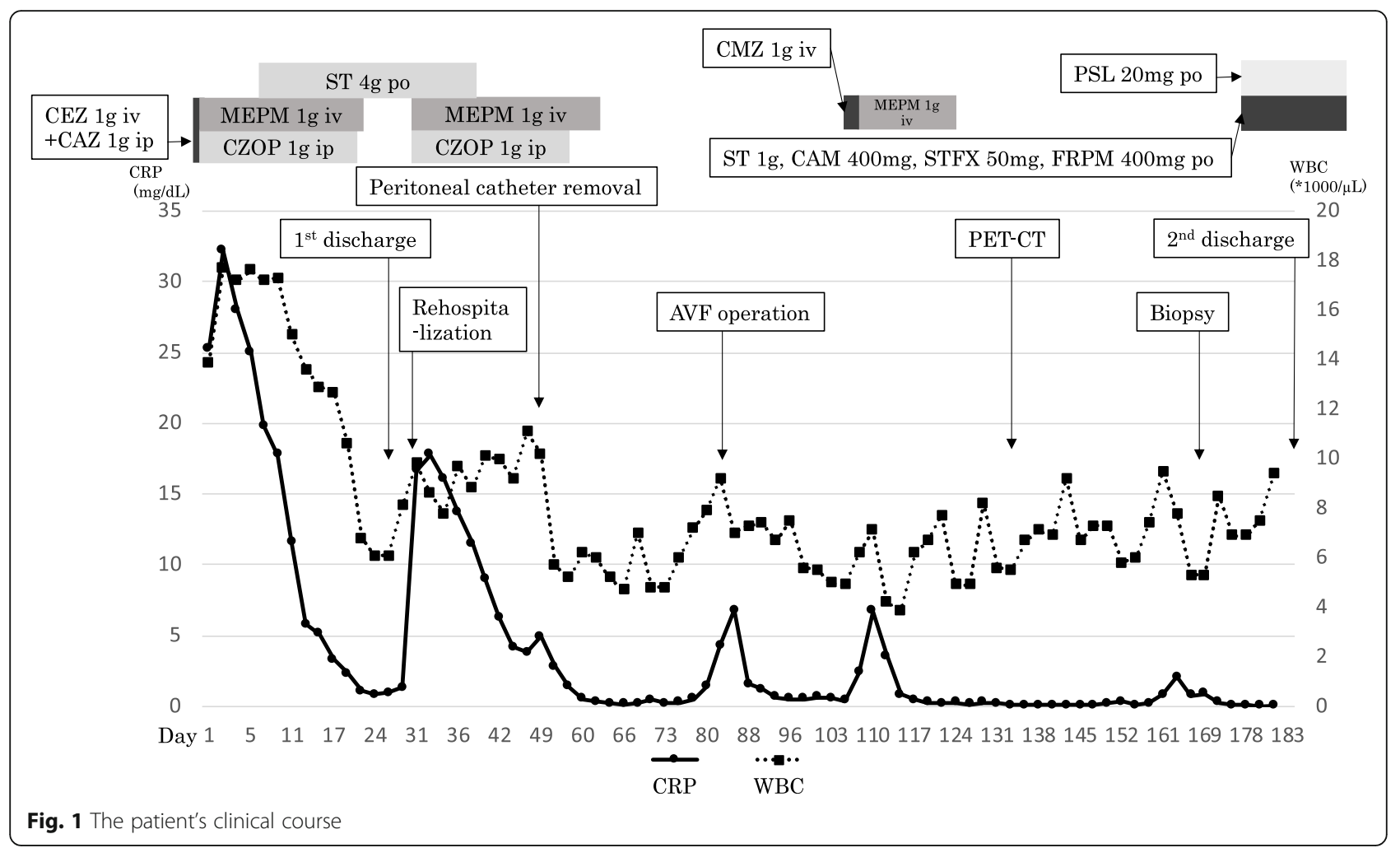

from the exit site. Acid-fast staining was then performed, and the result was found to be positive. To treat the patient's high fever and manage CRP levels $(16.7 \mathrm{mg} / \mathrm{dL})$, the treatment that was successful during her previous hospitalization was resumed, that is, CZOP via IP and MEPM via IV administration. With this treatment, her high fever and inflammation were again relieved. The acid-fast culture of the patient's dialysis effluent revealed the presence of nontuberculous mycobacteria; after that, we identified $M$. abscessus in the culture, and the patient's PD catheter was removed after 10 days. MEPM was discontinued because the patient's symptoms of peritonitis improved after the PD catheter was removed. However, she again complained of abdominal pain and diarrhea. An abdominal contrast-enhanced CT was performed that then revealed several new nodules resembling peritoneal cancer with enhancement in the abdominal cavity (Fig. 2a, (1) and (2)); we thought possibility of colon diverticulitis, but the nodules were separated from the intestinal tract on CT images. The gastroenterology department of the hospital was consulted and treatment with cefmetazole (CMZ) via IV administration was started; CMZ was recommended by gastroenterology who suspected enteritis. However, it was not effective. Hence, the treatment was changed from CMZ to MEPM via IV administration that again resulted in the improvement of the patient's condition. MEPM treatment was then discontinued. Fecal culture and fecal acid-fast culture results were negative. For the nodules in the peritoneal cavity, positron emission tomography-CT (PET-CT) was performed as peritoneal cancer or cancer of unknown primary organ was not ruled out. PET-CT results demonstrated a high uptake value in the nodule (Fig. $2 \mathrm{~b},(1)$ and (2)). The PET revealed a similar nodule that also demonstrated a high uptake value and was located around the previous external cuff of the PD catheter area (Fig. 2c, (1) and (2)). As it was difficult to perform biopsy of the other nodules in the peritoneal cavity, biopsy of that nodule was conducted. Biopsy results revealed epithelioid granuloma formation, Langhans giant cell and caseous necrosis in the nodule (Fig. 3), although we did not detect $M$. abscessus in the biopsy specimens; hence, it was assumed that the formation of that nodule and the other nodules in the peritoneal cavity were due to $M$. abscessus infection based on the timing of appearance and the similar degree of uptake on PET. As the patient contracted peritonitis several times in a short span of time, the high risk of developing encapsulating peritoneal sclerosis (EPS) was considered. Thus, treatment with prednisolone (PSL) through PO administration was started and $0.4 \mathrm{~g} /$ day of sulfamethoxazole and $80 \mathrm{mg} /$ day of trimethoprim (ST) were added to prevent pneumocystis pneumonia due to PSL administration. Moreover, PO administration of clarithromycin, sitafloxacin, and faropenem was started, and the patient was discharged on posthospitalization day 183; we continued 
(1)

(A)

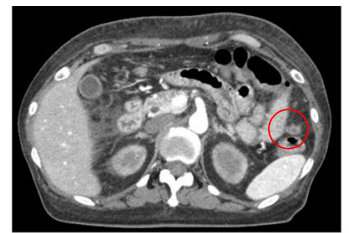

(B)

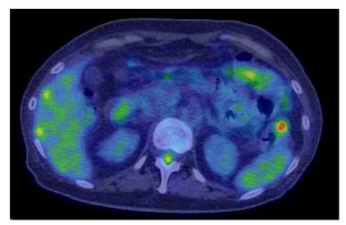

(C)

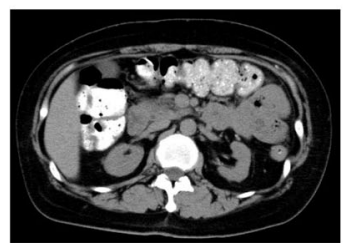

$(2)$
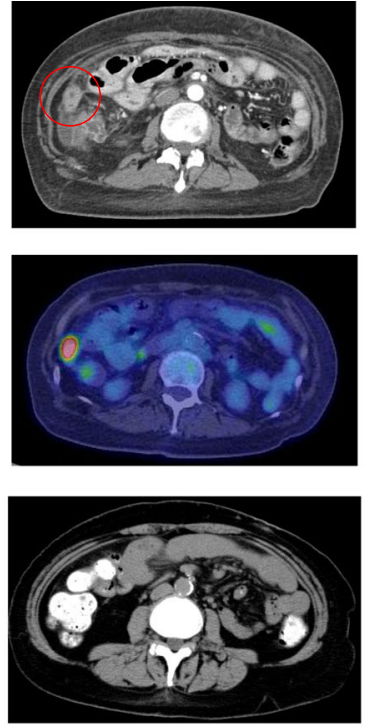

(3)
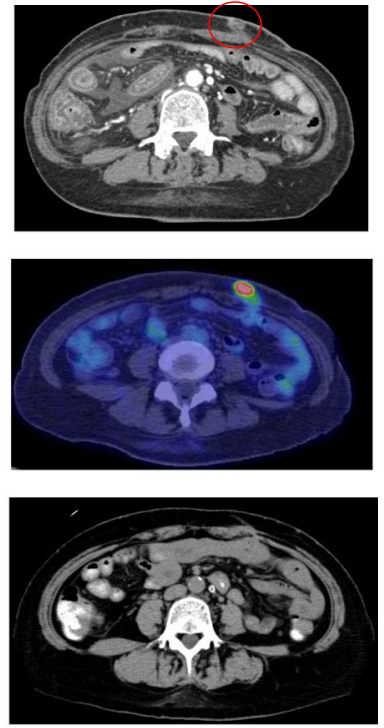

Fig. 2 Abdominal computed tomography (CT) images and positron emission tomography-CT (PET-CT) images, (1)-(3). a Nodules in the peritoneal cavity and located around the previous external cuff of the peritoneal dialysis catheter area on posthospitalization day 108, b PET-CT images on posthospitalization day 132, and c CT images revealed the disappearance of the nodule on posthospitalization day 267

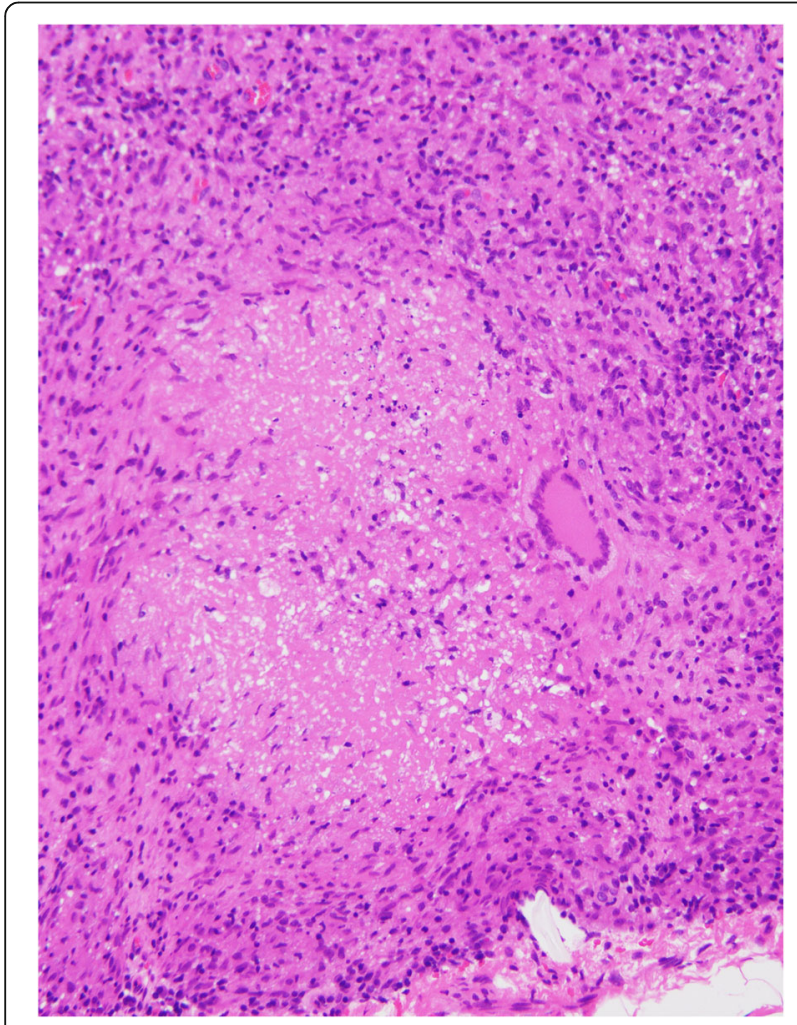

Fig. 3 The result of biopsy from the lesion around the external cuff clarithromycin, sitafloxacin, and faropenem 1 year after discharge. The PSL dose was gradually decreased to 15 $\mathrm{mg} /$ day on day $192,10 \mathrm{mg} /$ day on day $206,5 \mathrm{mg}$ /day on day 234 , and $2.5 \mathrm{mg} /$ day on day 295 and PSL and ST were discontinued on posthospitalization days 383 and 421, respectively. CT imaging on posthospitalization day 267 demonstrated the absence of nodules (Fig. 2c). Moreover, the nodules continued to disappear and the patient did not manifest any sign of recurrent peritonitis on posthospitalization day 456 .

\section{Discussion}

Peritonitis is a crucial complication that results in hospitalization or death in patients undergoing PD. PDrelated peritonitis caused by nontuberculous mycobacteria is uncommon; however, its incidence has increased in recent years [1]. It has been reported that more than half of the isolates, such as $M$. fortuitum and M. chelonae, are rapidly growing species that become positive on routine bacteriological cultures within $3-5$ days [1]. The treatment for peritonitis caused by nontuberculous mycobacteria has not been well-established and affected patients generally require catheter removal [1].

$M$. abscessus was reported as $M$. chelonae subspecies abscessus from a knee abscessus in 1953 [4], and $M$. abscessus was elevated to species status in 1992 [5]. M. abscessus has a complex structure and includes the following three subspecies: M. abscessus subsp. abscessus, M. abscessus subsp. massiliense, and M. abscessus subsp. bolletii. It belongs to a group of rapidly growing bacteria 
found in soil and water and causes several diseases such as skin, soft tissue, and respiratory disorders along with diseases that affect almost all human organs $[2,6]$. M. abscessus also causes PD-related infections such as exit-site infection and peritonitis, and some cases of diseases caused by $M$. abscessus have also been reported in Japan [7].

Since 1988, there have been 32 cases of PD-related infection caused by $M$. abscessus (Table 2) [3, 7-20], and 27 cases $(84.4 \%)$ needed catheter removal as the treatment. Furthermore, in only 6 among the 27 cases (22.2\%), PD was restarted after catheter removal. Thus, the PD-related infection caused by $M$. abscessus is believed to be the very crucial complication of PD as it often caused discontinuing PD.

Majority of the cases associated with M. abscessus infection have been reported from Asian countries, and the use of topical gentamicin cream may be the risk factor associated with PD-related nontuberculous mycobacterial infection $[10,14]$. In the case presented in this case, the patient had used gentamicin cream before her first admission to treat the exit-site infection. It is possible that this could have caused the infection. It has been reported that $M$. abscessus develops resistance to disinfectants due to the presence of large amounts of lipids in its cell wall, which can render benzalkonium chloride and chlorhexidine gluconate ineffective [9]. Another study reported that povidone iodine appeared to be a useful antiseptic against mycobacteria [21], whereas there is also a report

Table 2 Present reported cases of peritoneal dialysis-related infections caused by Mycobacterium abscessus

\begin{tabular}{lllll}
\hline Reference & Year & $\begin{array}{l}\text { Number of } \\
\text { PD-related } \\
\text { infection }\end{array}$ & $\begin{array}{l}\text { Number of } \\
\text { catheter } \\
\text { removal }\end{array}$ & $\begin{array}{l}\text { Number of } \\
\text { restarting } \\
\text { PD after } \\
\text { catheter } \\
\text { removal }\end{array}$ \\
\hline Ono et al. [8] & 2018 & 2 & 2 & 0 \\
Inoue et al. [7] & 2018 & 2 & 1 & 0 \\
Yoshimura et al. [9] & 2018 & 1 & 1 & 0 \\
Mooren et al. [10] & 2017 & 1 & 1 & 0 \\
Hibi et al. [3] & 2017 & 1 & 1 & 0 \\
Yang et al. [11] & 2015 & 2 & 2 & 0 \\
Jiang et al. [12] & 2013 & 3 & 3 & 0 \\
Tsai [13] & 2013 & 1 & 0 & 0 \\
Lo et al. [14] & 2013 & 6 & 4 & 2 \\
Jo et al. [15] & 2012 & 1 & 1 & 1 \\
Siddiqi et al. [16] & 2012 & 2 & 2 & 0 \\
Renaud et al. [17] & 2011 & 7 & 6 & 2 \\
Kameyama et al. [18] & 2007 & 1 & 1 & 0 \\
Ellis et al. [19] & 2005 & 1 & 1 & 1 \\
Slagle et al. [20] & 1998 & 1 & 1 & 0 \\
\hline
\end{tabular}

describing that neither antiseptic was effectively mycobactericidal under unclean conditions [22].

Peritonitis associated with $M$. abscessus infection is very difficult to treat as $M$. abscessus can inherently be resistant to most antibiotics such as antituberculous drugs [2, 3]. A macrolide-based regimen is frequently used to treat nonpulmonary diseases caused by $M$. abscessus, and imipenem may be clinically useful in treatment regimens for $M$. abscessus. In addition, surgical debridement may be a significant element of therapy [23]. Assessing the drug sensitivity of M. abscessus is extremely important; however, it takes approximately a month to identify the infecting organism and to obtain the information related to its drug sensitivity. Moreover, it is possible that $M$. abscessus can initially be misidentified as Corynebacterium species on routine bacterial culture tests, which results in the administration of ineffective treatment [24]. Hence, as an initial test for PD-related peritonitis, acid-fast culture should be performed in addition to routine bacterial culture tests. Patients with peritonitis associated with $M$. abscessus infection generally require PD catheter removal [1]. Even when patients undergo PD catheter replacement surgery, it is possible that peritonitis would recur due to $M$. abscessus infection [25]. If the PD catheter is not replaced or removed, treatment with antibiotics alone still results in a high failure rate [25]. Therefore, peritonitis due to $M$. abscessus infection in patients undergoing PD can possibly shift them to hemodialysis (HD) because of the removal of the PD catheter. In the present case, peritonitis associated with $M$. abscessus infection was treated with antibiotics without the removal of the PD catheter; however, patients generally require PD catheter removal to avoid early recurrence. Moreover, although peritonitis was improved by the removal of the PD catheter and through the antibiotic treatment, it recurred and new nodules appeared in the abdominal cavity and around the previous external cuff of the PD catheter area. To the best of our knowledge, this is the first report on the formation of nodules resembling peritoneal cancer in the abdominal cavity that developed due to PD-related peritonitis caused by $M$. abscessus, although it is not uncommon that nodules can be formed in the lungs in lung diseases associated with $M$. abscessus infection [26]. Patients with lung disease may undergo adjuvant resectional surgery. However, it is not a definitive surgery and not a radical cure; thus, patients are required to have treatment with antibiotics after the surgery [27]. In the present case, as well, surgical resection of intraperitoneal nodules for treatment and diagnosis was considered. However, as the inflammatory reaction and clinical symptoms improved, treatment with antibiotics was prioritized. It was also believed that surgical resection of intraperitoneal nodules could be difficult because of the 
difficulty in identifying the nodules during surgery, and CT-guided percutaneous biopsy of the nodules was also not considered to be desirable because sufficient sample volume to confirm whether the lesion occurred due to M. abscessus infection or not may not be obtained. In a previous study, PET-CT demonstrated a strong uptake, suggesting a malignant tumor on the lung nodule caused by $M$. abscessus [28]. Similarly, PET-CT demonstrated a strong uptake in our patient, but it was not useful in distinguishing malignant tumor from infection caused by M. abscessus.

It has been reported that the number of peritonitis episodes is a risk factor associated with the occurrence of EPS, a severe complication in patients undergoing PD [29]. Corticosteroid is a treatment of choice for EPS after infection has been controlled [30]. Thus, corticosteroids were also used as part of the treatment given to our patient. In the present case, the patient demonstrated no symptoms of ileus, and CT did not show any findings suggestive of EPS upon admission. Predicting and preventing EPS is extremely important in patients undergoing PD because of the close association of EPS with mortality. Currently, there are no prediction models for EPS for clinical usage and there is no single strategy to reduce the risk of developing EPS [31]. The patient presented in this case was managed with periodic blood tests and abdominal CT scans during follow-up visits after she was discharged. However, the literature lacks evidence of $\mathrm{CT}$ for patients in predicting EPS [31]. In the present case, although the patient's nodules in the peritoneal cavity disappeared on the CT image after discharge and antibiotic treatment was continued, it was necessary to perform a careful follow-up for EPS and monitor the recurrence of $M$. abscessus infection.

\section{Conclusion}

To the best of our knowledge, this report is the first to describe nodules resembling peritoneal cancer that were formed in the abdominal cavity after PD-related peritonitis associated with $M$. abscessus infection. PET-CT was not useful in distinguishing peritoneal cancer from nodules caused by $M$. abscessus. However, CT imaging performed after antibiotic treatment showed the disappearance of the nodules.

\footnotetext{
Abbreviations

PD: Peritoneal dialysis; CT: Computed tomography; WBC: White blood cell; CRP: C-reactive protein; CEZ: Cefazolin; IV: Intravenous; CAZ: Ceftazidime; IP: Intraperitoneal; MEPM: Meropenem; CZOP: Cefozopran; ST: Sulfamethoxazole and trimethoprim; PO: Peroral; CMZ: Cefmetazole; PET$C T$ : Positron emission tomography-CT; EPS: Encapsulating peritoneal sclerosis; PSL: Prednisolone; HD: Hemodialysis
}

\section{Authors' contributions}

KT drafted the first manuscript. KM, SK, Fl, and TY managed the patient. YS coordinated the data analysis and helped with writing the manuscript. All authors participated in discussions and read and approved the final manuscript.

\section{Funding}

None.

\section{Availability of data and materials}

All data generated or analyzed during this study are included in this published article.

Ethics approval and consent to participate

Not required because this is a case report

\section{Consent for publication}

Written consent was obtained from the patient to publish this case report and accompanying images. A copy of the written consent is available for review by the editor of this journal.

\section{Competing interests}

The authors declare that they have no competing interests.

Received: 27 December 2019 Accepted: 13 April 2020

Published online: 28 April 2020

\section{References}

1. Li PK, Szeto CC, Piraino B, de Arteaga J, Fan S, Figueiredo AE, et al. ISPD peritonitis recommendations: 2016 update on prevention and treatment. Perit Dial Int. 2016 Sep 10;36(5):481-508.

2. Lee MR, Sheng WH, Hung CC, Yu CJ, Lee LN, Hsueh PR. Mycobacterium abscessus complex infections in humans. Emerg Infect Dis. 2015 Sep;21(9): $1638-46$.

3. Hibi A, Kasugai T, Kamiya K, Kamiya K, Ito C, Kominato S, et al. Peritoneal dialysis-associated catheter infection caused by Mycobacterium abscessus in an elderly patient who was successfully treated with catheter removal. CEN Case Rep. 2017 Nov;6(2):175-9.

4. MOORE M, FRERICHS JB. An unusual acid-fast infection of the knee with subcutaneous, abscess-like lesions of the gluteal region; report of a case with a study of the organism, Mycobacterium abscessus, n. sp. J Invest Dermatol. 1953 Feb;20(2):133-69.

5. Kusunoki S, Ezaki T. Proposal of Mycobacterium peregrinum sp. nov., nom rev., and elevation of Mycobacterium chelonae subsp. abscessus (Kubica et al.) to species status: Mycobacterium abscessus comb. nov. Int J Syst Bacteriol. 1992 Apr;42(2):240-5.

6. Brown-Elliott BA, Wallace RJ Jr. Clinical and taxonomic status of pathogenic nonpigmented or late-pigmenting rapidly growing mycobacteria. Clin Microbiol Rev. 2002;15(4):716-46 Review.

7. Inoue H, Washida N, Morimoto K, Shinozuka K, Kasai T, Uchiyama K, Tokuyama H, Wakino S, Itoh H. Non-tuberculous mycobacterial infections related to peritoneal dialysis. Perit Dial Int. 2018 Mar-Apr;38(2):147-9.

8. Erina Ono, Eiichiro Uchino, Keita P. Mori, Hideki Yokoi, Naohiro Toda, Kenichi Koga, Masato Kasahara, Takeshi Matsubara and Motoko Yanagita. Peritonitis due to Mycobacterium abscessus in peritoneal dialysis patients: case presentation and mini-review. Renal Replacement Therapy. 2018 4:52.

9. Yoshimura R, Kawanishi M, Fujii S, Yamauchi A, Takase K, Yoshikane K, Egawa M, Shiina H, Ito T. Peritoneal dialysis-associated infection caused by Mycobacterium abscessus: a case report. BMC Nephrol. 2018 Nov 29;19(1): 341.

10. Mooren VHJF, Bleeker MWP, van Ingen J, Hermans MHA, Wever PC. Disseminated Mycobacterium abscessus infection in a peritoneal dialysis patient. IDCases. 2017 May 4;9:6-7.

11. Yang TK, Lee JJ, Lu PL, Kuo HT, Kuo MC, Chen HC. Peritoneal dialysisassociated peritonitis caused by Mycobacterium abscessus. Perit Dial Int. 2015 May-Jun;35(3):369-71.

12. Jiang SH, Roberts DM, Clayton PA, Jardine M. Non-tuberculous mycobacterial PD peritonitis in Australia. Int Urol Nephrol. 2013 Oct;45(5): 1423-8.

13. Tsai SF. Catheter related infection due to Mycobacterium abscessus in a patient under peritoneal dialysis. Ther Apher Dial. 2013 Jun;17(3):349-50. 
14. Lo MW, Mak SK, Wong YY, Lo KC, Chan SF, Tong GM, Lo KY, Wong PN, Tse CW, Kam KM, Wong AK. Atypical mycobacterial exit-site infection and peritonitis in peritoneal dialysis patients on prophylactic exit-site gentamicin cream. Perit Dial Int. 2013 May-Jun;33(3):267-72.

15. Jo A, Ishibashi Y, Hirohama D, Takara Y, Kume H, Fujita T. Early surgical intervention may prevent peritonitis in cases with Tenckhoff catheter infection by nontuberculous mycobacterium. Perit Dial Int. 2012 Mar-Apr; 32(2):227-9.

16. Siddiqi N, Sheikh I. Peritonitis caused by Mycobacterium abscesses in patients on continuous ambulatory peritoneal dialysis. Saudi J Kidney Dis Transpl. 2012 Mar;23(2):321-4.

17. Renaud CJ, Subramanian S, Tambyah PA, Lee EJ. The clinical course of rapidly growing nontuberculous mycobacterial peritoneal dialysis infections in Asians: a case series and literature review. Nephrology (Carlton). 2011 Feb;16(2):174-9.

18. Kameyama H, Mori Y, Kimura T, Sugishita C, Adachi T, Sonomura K, Kusaba T, Tanda S, Kishimoto N, Okigaki M, Hatta T, Matsubara H. A case report of Mycobacterium abscessus peritonitis in a peritoneal dialysis patient. Ther Apher Dial. 2007 Dec;11(6):449-51.

19. Ellis EN, Schutze GE, Wheeler JG. Nontuberculous mycobacterial exit-site infection and abscess in a peritoneal dialysis patient. A case report and review of the literature. Pediatr Nephrol. $2005 \mathrm{Jul} ; 20(7): 1016-8$.

20. Slagle KM, Oblack DL. Mycobacterium abscessus peritonitis: a case report. Clin Lab Sci. 1998 Jul-Aug;11(4):206-8.

21. Rikimaru T, Kondo M, Kondo S, Oizumi K. Efficacy of common antiseptics against mycobacteria. Int J Tuberc Lung Dis. 2000 Jun;4(6):570-6.

22. Cheng A, Sun HY, Tsai YT, Wu UI, Chuang YC, Wang JT, Sheng WH, Hsueh PR, Chen YC, Chang SC. In vitro evaluation of povidone-iodine and chlorhexidine against outbreak and nonoutbreak strains of Mycobacterium abscessus using standard quantitative suspension and carrier testing. Antimicrob Agents Chemother. 2017 Dec;21:62(1).

23. Griffith DE, Aksamit T, Brown-Elliott BA, Catanzaro A, Daley C, Gordin F, Holland SM, Horsburgh R, Huitt G, lademarco MF, Iseman M, Olivier K, Ruoss S, von Reyn CF, Wallace RJ Jr, Winthrop K; ATS Mycobacterial Diseases Subcommittee; American Thoracic Society; Infectious Disease Society of America. An official ATS/IDSA statement: diagnosis, treatment, and prevention of nontuberculous mycobacterial diseases. Am J Respir Crit Care Med. 2007 Feb 15;175(4):367-416.

24. Williamson JC, Miano TA, Morgan MR, Palavecino EL. Fatal Mycobacterium abscessus endocarditis misidentified as Corynebacterium spp. Scand J Infect Dis. 2010 Mar;42(3):222-4.

25. Huang YC, Liu MF, Shen GH, Lin CF, Kao CC, Liu PY, Shi ZY. Clinical outcome of Mycobacterium abscessus infection and antimicrobial susceptibility testing. J Microbiol Immunol Infect. 2010 Oct;43(5):401-6.

26. Nagano H, Kinjo T, Nei Y, Yamashiro S, Fujita J, Kishaba T. Causative species of nontuberculous mycobacterial lung disease and comparative investigation on clinical features of Mycobacterium abscessus complex disease: a retrospective analysis for two major hospitals in a subtropical region of Japan. PLoS One. 2017 Oct 23;12(10):e0186826.

27. Kang HK, Park HY, Kim D, Jeong BH, Jeon K, Cho JH, Kim HK, Choi YS, Kim J, Koh WJ. Treatment outcomes of adjuvant resectional surgery for nontuberculous mycobacterial lung disease. BMC Infect Dis. 2015 Feb 19;15: 76.

28. Gil BM, Chung MH, Kim YD, Kim YH, Kang HS, Kim IJ. Aggressive mycobacterium abscessus on repeated exogenous lipoid pneumonia in the right middle lobe. Ann Transl Med. 2019 May;7(9):206.

29. Yamamoto R, Otsuka Y, Nakayama M, Maruyama Y, Katoh N, Ikeda M, Yamamoto H, Yokoyama K, Kawaguchi Y, Matsushima M. Risk factors for encapsulating peritoneal sclerosis in patients who have experienced peritoneal dialysis treatment. Clin Exp Nephrol. 2005 Jun;9(2):148-52.

30. Danford CJ, Lin SC, Smith MP, Wolf JL. Encapsulating peritoneal sclerosis. World J Gastroenterol. 2018 Jul 28;24(28):3101-11.

31. Brown EA, Bargman J, van Biesen W, Chang MY, Finkelstein FO, Hurst $H$, Johnson DW, Kawanishi H, Lambie M, de Moraes TP, Morelle J, Woodrow G. Length of time on peritoneal dialysis and encapsulating peritoneal sclerosis - position paper for ISPD: 2017 update. Perit Dial Int. 2017 Jul-Aug;37(4): 362-74.

\section{Publisher's Note}

Springer Nature remains neutral with regard to jurisdictional claims in published maps and institutional affiliations.

\section{Ready to submit your research? Choose BMC and benefit from}

- fast, convenient online submission

- thorough peer review by experienced researchers in your field

- rapid publication on acceptance

- support for research data, including large and complex data types

- gold Open Access which fosters wider collaboration and increased citations

- maximum visibility for your research: over $100 \mathrm{M}$ website views per year

At BMC, research is always in progress.

Learn more biomedcentral.com/submissions 